\title{
Kültür Endüstrisinin Yeniden Üretiminde Kitle İletişim Araçlarının Görevleri: Theodor W. Adorno Değerlendirmesi
}

\author{
DOI: $10.26466 /$ opus.706877
}

\author{
Ülhak Çimen* \\ * Dr. Öğr. Üyesi, Atatürk Üniversitesi, İletişim Fakültesi, Erzurum, Türkiye \\ E-Posta: ulhakcimen@gmail.com \\ ORCID: $0000-0002-7307-4874$ \\ Öz
}

Adorno'nun sistem karşıtı tepkisinin en önemli ayağı geliştirmiş olduğu kültür endüstrisi analizidir. Adorno'ya göre kültür, sadece sınıf çıkarlarının bir yansıması değil toplumu meydana getiren bütün bileşenleri (ekonomi, politika, sanat, ahlak, din vb) etkileyen olgudur. Kültür endüstrisi ise toplumsal yaşam içerisindeki bütün kültür bileşenlerinin alınıp satılması ve nihayetinde bireylerin ticarileşmesini açıklamaktadır. Düşünür kültür endüstrisinde insanın, toplumun ve özge kültürün sömürüldüğünü iddia etmektedir. Ticarileşen bireyler hem sistem tarafindan ticari metaya dönüştürülmekte hem de kategorize edilerek tek tipleştirilmekte ve kapitalist dizgeye uyumlu hale getirilmektedir. Adorno teknolojiye ve kitle iletişim araçlarına karşı olumsuz bir tavır takınmamaktadır. Adorno'nun eleştirisini yaptığı şey tekniği ve teknolojiyi elinde tutan sistemdir. Kültür tekellerinin propagandasın yapan kitle iletişim araçlarn sistem için katalizör görevindedir. Düşünüre göre kültür endüstrisi toplumsal yapıda adaletsizlik meydana getirmekte ve bu adaletsizlik kitle iletişim araçlarıla sürekli yayılmaktadır. Kültür endüstrisinin dağıtımını yapan kitle iletişim araçları kişileri tecrit ederek yüz yüze iletişimden uzaklaştırmakta ve sistemin kodlarına tabi kılmaktadır. Adorno'ya göre bireyin ve toplumun kendilerine yapılan kötülükleri görmezden gelerek kültür endüstrisine karşı besledikleri sevgi, sistemin kurnazlığını bile aşmıştır. Kapitalist sistem kişileri şeyleştirirken artık egemenliğe ihtiyaç duymamaktadır. Çünkü gönüllü köleliklerin yaşandığı hegemonya dünyasında bireyler sisteme uyum sağlayabilmek için can atmaktadır.

Anahtar Kelimeler: Theodor Adorno, Kültür, Kültür Endüstrisi, Kitle İletişim Araçları, Hegemonya. 


\title{
The Responsibilities Of Mass Media In The Reproduction Of The Culture Industry: The Assessment Of Theodor W. Adorno
}

\begin{abstract}
The most important mainstay of Adorno's anti-system response is the cultural industry analysis. According to Adorno, culture is not only a reflection of class interests, but a phenomenon that affects all components that make up society (economy, politics, art, morality, religion, etc.). The culture industry, on the other hand, explains the buying and selling of all cultural components in social life and eventually the commercialization of individuals. The thinker considers that human, society and native culture are exploited in the culture industry. Commercialized individuals are transformed into commercial commodities by the system, categorized and uniformized and harmonized with the capitalist system.Adorno does not take a negative attitude towards technology and mass media. What Adorno criticizes is the system that holds the technique and technology. Mass media, which propagate culture monopolies, act as catalysts for the system. The thinker thought that the culture industry creates injustice in the social structure and this injustice is constantly spreading by mass media. Mass media distributing the culture industry isolates people away from face-to-face communication and subordinates the codes of the system. According to Adorno, the love of the individual and the society for the culture industry by ignoring the evil done to them has even exceeded the cunning of the system. The capitalist system no longer needs sovereignty while reification of people. Because in the world of hegemony where voluntary slavery is experienced, individuals are eager to adapt to the system.
\end{abstract}

Keywords: Theodor Adorno, Culture, Culture Industry, Mass Media, Hegemony. 


\section{Giriş}

Theodor Adorno, Toplumsal Araştırmalar Enstitüsü ve Eleştirel Teori olarak bilinen Frankfurt Okulu'nun en önemli düşünürlerinden birisi; kültür endüstrisi konusunda ise okulun sözcüsüdür (Slater 1998). Adorno, kültür endüstrisi görüşlerini açıklarken ideolojiyi temele alarak toplumsal şartların farklı bir perspektifle değerlendirilmesi gerektiğini öne sürmüştür. Bu perspektifin oluşabilmesi için eleştirel bilinç şarttır. Eleştirel bilinç, mevcut şartların insanlık adına olması gereken şartları sunmadığını göstermeli ve kültürün egemenliğinde yer alan siyaset, ekonomi, toplum ve genelinde bütün yapıları ters yüz edebilmelidir.

Adorno'ya göre kültür motifleri içerisinde en uzun ömürlü olanlar yalan üstüne kurulu olanlardır. Kültürün insanlara uygun bir toplum inşa ettiği söylemi bilinçli bir şekilde yayılmakta ve bu durum ideolojiye dönüştürülmektedir (Slater 1998, s.91). Kültüre itaat etmek, sistem tarafindan belirlenen davranıs formlarına uygun şekilde davranmaya yol açmakta ve insanlık felaketlere gebe bırakılmaktadır. Kapitalizm fikirleri, hipotezleri, eylemleri ve davranışları deliller/ispatlar ile ortaya koymada referansları öylesine kendi bilincine bağlamıştır ki doğru veya yanlış olan her şey mutlak anlamda sistemin argümantasyonuna göre belirlenmektedir (Adorno 2013, s.45).

Başat ideolojinin eylemlerin geçerliliğinde bir durumu mantıksal kanıt olarak sunması nesnellikle örtüşmemektedir. Hakikatin yalan yalanın ise hakikat olduğu bir dünyada bütün açılama, mesaj ve haberler kültür endüstrisinin süzgecinden geçmektedir (Adorno 2017(a), s.113). Kültür endüstrisinin olurunu almayan hiçbir gerçeklik onaylanmamakta ve geçerli sayılmamaktadır. Nesnellik sistemin belirlemiş olduğu mantıksal kanita boyun eğmiştir. Mantıksal kanıt doğru ve yalanı himayesine aldığı için kitle iletişim araçlarının mesajlarında değer ölçütü sistem tarafından belirlenmektedir.

Nesnellik toplumları yöneten özneler tarafından belirlenmektedir. Kültür endüstrisi çağında nesnellik gerçek niteliğini kaybederek belirli öznelerin belirlenimlerine tabi kılınmıştır. Nesnelliği belirleyen özne ve özne grubu bireyin düşünememesini ve güçsüz kalmasını istemektedir (Adorno 2017(a) s.74). Aynı şekilde kültür endüstrisi hayal kurma yeteneğinin azalmasına yol açmıştır. İnsanı istediği şekilde alıp işleyen, ayrıştıran, dönüştüren ve form haline getiren sistem, ilerleme kavramın temele oturtarak belir- 
lenen hedeflerin gerçekleştirilmesinde kişilere çeşitli roller belirlemiştir. Belirlenen bu rollerdeki kişilerin sistemin belirlediği imgelerin, düşüncelerin, bilinçlerin ve hayallerin dışına çıkmasına müsaade edilmemektedir. Bu anlamda düşüncenin kıymet kazanabilmesi için sistemin belirlediği çerçevenin dışına çıkılmaması gerekmektedir (Adorno ve Horkheimer 2014 s.59).

Adorno öznelliğin mutlak anlamda toplumsal bileşenlerle birlikte gelişmesi gerektiğini savunmaktadır. Araçsallaştırılmış öznel aklın tek yanlı üstünlügüne karşı doğru teoriden beslenecek nesnel aklı kıymetli görmek gerekmektedir. Çünkü bütünlüğün karşıtı olarak tanımlanan öznel akıl mevcut sistemde özgür değildir. İnsanlığın tamamına katkı sunacak özgürlük özel ve genel çıkarların birliğiyle ortaya çıkabilecek bir özgürlüktür. Lakin kitle insanının pozitif özgürlük bağlamında toplumsal bütünlüğe katkı sağlayabilecek bilinci söz konusu değildir. Kitle insanı sadece sistemin insanları şeyleştirmesine katkı sağlayabilmekte ve mütemadiyen sisteme hizmet etmektedir.

“İnsanı özgürleştirmeye çabalayan Aydınlatma, ironik bir şekilde, etkili araçlarla, daha önce hiç olmadığı kadar, insanı köleleştirmeye hizmet ediyordu. Eylem için açık bir alternatif ortaya çıkmadığı sürece, kültür endüstrisinin hissizleştiren gücünden hala kaçabilecekler için tek yol, geride kalan olumsuzlamanın kalıntılarını korumak ve geliştirmekti" (Jay 2014, s.424).

Kültür endüstrisinde iletişim araçları tecrite yol açarak kişileri yüz yüze iletişimden uzaklaştırmaktadır (Adorno ve Horkheimer 2014, s.293). İnsanların kendi aralarında konuşmalarını engelleyebilmek için önceleri muazzam bir çaba gösterilirken bu araçların gelişmesiyle birlikte artık her şey otomatikleşmiştir. İletişim artık insanları birbirlerinden uzaklaştırmaktadır. İletişim, insanları birbirinden ayırarak aynı düzlemde birbirlerine benzetmektedir (Adorno ve Horkheimer 2014, s.294). Kültür endüstrisinin emtialarını mütemadiyen öven kitle iletişim araçları dizgeye hizmet ederken bireyler üzerindeki baskıya katkı sunmakta ve kişisel dirençleri yok etmektedir.

\section{Çalışmanın Amacı ve Önemi}

Adorno'nun kültür endüstrisi eleştirisi teknolojiyi ve kitle iletişim araçlarını elinde tutanların art niyetli olduğu tezine dayanmaktadır. Teknolojinin ve kitle iletişim araçlarının gelişme aşamasında olduğu dönemde kültürün toplumsal yapı üzerindeki etkisi yavaş yavaş ortaya çıkmaktaydı. Kültürün 
bu etkisinin günümüzde devam edip etmediği veya ne şekilde devam ettiği merak edilen konuların başında gelmektedir.Bizi bu çalışmaya yönelten saik; kültür endüstrisinin günümüz dünyasında etkisini anlama çabasıdır.

Şeyda Öztürk Adorno'nun Müzik Yazıları kitabının sunuşunda günümüzde kitle iletişim araçlarının ve genelinde bütün teknolojilerin toplumsal yaşamımıza mutlak etkide bulunduğunu, bu etkinin kültür endüstrisinin başatlığıyla gerçekleştiğini ve bu nedenle Adorno'nun eleştirisinin güncelliğini koruduğunu iddia etmektedir (Adorno 2018 s.19). Bu bağlamda teknolojinin ve teknoloji paralelinde kitle iletişim araçlarının mütemadiyen geliştiği bir dünyada kültürün insanlar ve toplumlar üzerindeki etkisinin Adorno'nun vurguladığı şekilde olup olmadığını anlamayı hedefleyen çalışma önemli olarak değerlendirilmektedir.

\section{Kavramsal Çerçeve}

Çalışmamızın kavramsal çerçevesini kültür ve kültür endüstrisi kavramları oluşturmaktadır.

Kültür: Adorno kültür endüstrisinin temel bileşeni olan kültüre karşı olumsuz bir tavır takınmıştır. Ona göre kültür bir sistem ideolojisidir ve bu ideolojinin reklamını yapmak için bütün kurumların canhıraş biçimde çaba göstermesi gerekmektedir.

"Kültür, insana yaraşan bir toplumda yaşandığı yanılsamasını yaratmakta, bütün insan ürünlerinin temelinde yatan maddi koşulları gözlerden saklamakta ve rahatlatıp uyuşturarak, varoluşun kötü ekonomik belirleniminin sürüp gitmesine hizmet etmektedir" (Adorno 2017(a), s.47).

Kültür, diyalektik dolanımlar bağlamında ancak bütünsel bir değerlendirmede anlam kazanabilmektedir. Dolayısıyla toplumu ve dünyayı doğru analiz edebilmek için kültürün doğru değerlendirilmesi hayati önem taşımaktadır. Kültür, iletişimin gerçek niteliğiyle değerlendirilmeyip sistemin belirlediği esaslar çerçevesinde değer kazandırılan ideolojik bir anlayışı açıklamaktadır. Kültür kavramı maddi ve maddi olmayan bütün toplumsal yapı ürünlerinin üst aklın isteklerine göre biçimlendirilmesine karşılık gelmektedir. Nesnel aklı yöneten üst aklın endüstri haline getirdiği kültür oluşumlarının dağıtılmasında kitle iletişim araçları hayati önem taşımaktadır (Kejanlıŏlu 2005, s.185). 
Kültür Endüstrisi: Adorno kültür eleştirisi yaptığı yazıların ilk bölümlerinde kültür endüstrisi yerine kitle kültürü kavramını kullanmış ancak daha sonra kültür endüstrisinde sabit kalmıştır. Kitle kültürü yerine kültür endüstrisini tercih etmesine gerekçe olarak kültürün aşağıdan yukarıya yani kitleler tarafından yükseltilmemesini bunun aksine yukarından aşağıya yani sistem tarafından dayatılmasını göstermiştir (Akt: Kejanlığlu 2005, s.184).

Kültür endüstrisinin birleştirici ve bütünleştirici işlevi;

“...bireyi yok etmesi, araçsal akla tabi kılması, düşünceyi yenmesi, çokluğu tek hale getirmesi şeklinde sıralanmaktadır" ( Kejanlığlu 2005, s.190).

\section{Kültür Endüstrisi Nosyonu}

Ekonominin fetişleştirilerek kültürün önemsiz hale getirilmesi toplumsal yapıyı anlamada ciddi problemlere yol açmıştır (Jay 2014, s.253). Adorno ekonomi ve siyasetin fetişleştirilmesine karşı bir duruş gösterdiği gibi aynı şekilde kültürü de toplumsal mekanizmalardan bağımsız görmenin sakıncalarını ortaya koymaya çabalamıştır. Onun için insani bir emeğin görünümü olan kültür ile maddi varoluşun temelinde bulunan ekonomi kesinlikle karşıt olarak ele alınmamalıdır ve bunlar arasında mutlak bir diyalektik ilişki söz konusudur. Adorno'ya göre alt yapı ve üst yapı arasındaki ilişki mutlak anlamda kuvvetler alanı içerisinde değerlendirilmelidir.

Kitle kültürünün tekelci ortamında bireyselliğe kıymet yükleyen insanın dünyanı dönüştürülmesi amaciyla verdiği mücadele kıymete değerdir. Ancak bu mücadele önceden verilen mücadelelere göre çok daha zor ve meşakkatlidir. Çünkü varlığını mütemadiyen güçlendiren dünya dizgesi, görünen ve görünmeyen bütün her şeyi istediği biçimde kullanabilmektedir (Adorno 2017(a), s.36-37). Adorno'ya göre kültür endüstrisi toplumsal yap1da adaletsizlik meydana getirmekte ve bu adaletsizlik kitle iletişim araçlariyla yeniden üretilmektedir (Akt:Jay 2014, s.340). Doğru teorinin yapması gereken şey; kültür endüstrisi ile sisteme bağımlı hale gelen bireyleri bilinçli hale getirmesidir. Demokratik olmayan kitle kültürü sisteme tabi bireyler oluştururken ideolojik bir bakış açısı sergilemektedir ve bu ideoloji sahte kültürler oluşturarak tüm bileşenleriyle insanları şeyleştirmektedir. Artık yüksek kültür ve düşük kültür ayrımından bahsetmek olanaksızdır. Çünkü kitle kültürünün oluşturduğu toplumsal yapı ayrımları ortadan kaldırarak bütün kültür biçimlerini kendi yönlendirmelerine tabi kılmıştır. 
Bir şeyi kendi ötesinde düşünme yani açıllğa kavuşturmaya yönelik düşünme metafiziktir (Adorno 2017(b), s.116). Adorno, metafiziği kesin anlamda eleştirel ve kurtarıcı bir gayeyi gerçekleştirmede kurtarıcı olarak görmektedir. Ona göre metafizik;

“...aydınlanmış aklın hem gelenek kavramları ve fikirleri, kendi başına var olan fikirleri mitolojik olmakla eleştirdiği hem de aynı zamanda tam da aklın uygulanması hatta kendi akılcı kaynakları içinde yeni baştan üretmesi aracilığıyla aklın tahrip etmiş olduğu bu kavramları kurtarmak ya da onarmak istediği yerde hep bulunmaktadır" (Adorno 2017(b), s.90). Adorno'ya göre kültür endüstrisinde sistemin anlam yüklediği kavramlara güven duyulmamalıdır (Adorno ve Horkheimer 2014, s.43).

Kültür endüstrisinde mülkiyet sahipliği önemsiz hale getirilmekte; yaşanılan yerde sürekli kalmama ve değiştirilebilirlik ideolojik bir hale sokulmaktadır. Güncel kültürün ahlakı bunu gerektirmektedir (Adorno 2017(a), s.43). Hüküm altındaki kitlelerin hükmeden sistem ahlakını onlardan daha fazla sahiplenmeleri başarı söylemiyle açklanmaktadır. Kitlelerden ahlaki anlamda beklenen onları köleleştiren sistem ideolojisine sahip çımalarıdır (Adorno ve Horkheimer 2014, s.179).

\section{Kültür Endüstrisi ve Kültür İlişkisi}

Geleneksel doğruluk, güzellik ve iyilik değerlerinin mütemadiyen kültür bağlamında insanlara sunulmasına Adorno diriltilmiş kültür adını vermektedir (Adorno 2017(b), s.196). Bu kültür biçimi yok ettiği yıkıntılara benzemekte; kendini yeniden üreterek ideoloji haline gelmektedir. İnsanlığın kurtuluşu ve ortadaki gerçeklik aslında iki durumun birbiriyle uyuşmazlığını göstermektedir. Sistem öğretisindeki kültürün devam etmesi ve erkini sürdürmesi için mücadele eden yani kültürü destekleyen herkes kültürün sahteliğine ortak olmakta; baskın ideolojiye hizmet etmektedir ki bu kültür insanlığa fayda sağlamayan bir kültürdür. Adorno'ya göre sürekli kendini yenileyen ve yeniden canlandırılan kültürün kofluğunu (Adorno 2017(b), s.183) mevcut düşünce biçimleriyle anlayabilmek imkânsızdır. Sessiz kalma biçimleri sisteme hizmet etmenin diğer bir yoludur. İnsan hiçbir şey söylemeyerek sadece kendi yetersizliğini ve iktidarsızlığın ortaya koymamakta dizgenin himayesindeki nesnelliği onaylamaktadır. İktidarın ağında düş- 
müş olan kültür nesnelliğin himayesinde endüstri haline getirilmiş olan şeydir.

Kültür bir zamanlar insanları dünyaya karşı savunan değere sahipken şimdilerde bu değer evrensel ideoloji tarafından tarumar edilmiştir. Yani kültür haute bourgeoisie (yüksek burjuvazi) tarafından gösteriş öğesine çevrilmiştir (Adorno 2017(a), s.195). Kültür, özdeş aklın bir ürünü değil empirik varoluşun bir çeşit sürdürülebilir ideolojisidir. Kültür endüstrisinde birey ve sistem arasındaki anlaşma bireyden bağımsız biçimde oluşturulmakta; birey de bu anlaşmayı sorgulamadan kabul etmekte ve ritüelleştirilmiş bir dolaşımda mütemadiyen teyit etmektedir. Kitle iletişim araçlarının sunmuş olduğu kodların içselleştirilmesi bu anlaşmanın kabul edildiğinin kanıtıdır.

Kamusallaştırılmış kültür endüstrisinde bireysel düşüncelere ve kararlara saygı veriliyormuş izlenimi uyandırılmaktadır. Dürüstlükten uzak bu saygıda mevcut dizge düşünceleri ve saygıları himayesine alarak ideolojik geçerliliğini benimsetecek devinim mekanizmaları üretmektedir. Bu devinim, düşünce ve kararların mevcut geçerliliğe ne şekilde entegre edilebileceği üzerine yoğunlaşmaktadır. Kültür endüstrisini dünyanın büyük bir çoğunluğuna yayılmış bir çeşit ideoloji olarak tanımlayabilirsek bu tanımlamada insan ve özge kültürün sistemli bir biçimde sömürüldüklerini de görebilmeliyiz (Adorno 2017(a), s.154). Bu bağlamda kültürün ticari karakteri, pratik yaşam ile kültür arasındaki farkı silikleştirmektedir. Yani kültür endüstrisinin kendini gerçekleştirdiği toplumsal yapıda insanlar doğru bir hayat sürdüklerine inandırılmaktadır (Adorno 1991, s.53).

İnsanlar çalışmaya kutsallık atfedilen bir çağda mütemadiyen çalışmak zorunda olduklarını hissetmekteler ve bu çalışma biçiminde kültür yeniden üretilmektedir. Buradaki problem şudur:

“Çalışma kesin, garantili bir biçimde çalışanların hayatlarını yeniden üretmiyor, onları çalışmaya ikna edenlerin hayatlarını yeniden üretiyor sadece. İnsanları çalışmaya razı etmek için emeğin kendinde şey olduğu safsatasinı yutturmak gerekiyor"(Adorno 2013, s.15).

Adorno yaşanılan toplumda çalışmanın toplama kamplarında çalışmaya benzediğini düşünmektedir. Adorno'ya göre insanlar çalışırken ne için çalıştıklarını düşünmemelidir. Çalışmanın soyut zorunluluğuna değer atfedilmesi düşünceyi gereksiz hale getirmekte ve böylelikle kültür endüstrisi yeniden üretilmektedir. İnsanlara dinlenme saati diye bahşedilen zaman diliminde farkına varılmadan kültürün yeniden üretimi devam etmektedir. 
Mevcut kültür insanlara düşünmeleri için gerçek anlamda zaman tanımamakta; insanları iyiliğe taşıyacak teori ve praksis biçimlerinin önüne geçmekte ve böylelikle toplum kendini yeniden üretmektedir.

\section{Kültür Endüstrisi Teknoloji İlişkisi}

Adorno teknik ve teknolojiye karşı olumsuz bir tavır takınmamaktadır. Adorno'nun eleştirisini yaptığı şey tekniği ve teknolojiyi elinde tutan sistemdir. Kitle sanatı gibi yüksek sanat da kapitalizm lekeleri taşımaktadır; dolayısıyla lekelenmiş bir şeyin teknolojik dönüşümünde araçları suçlamamak gereklidir. Tekniğin ilerlemeci ve rasyonel kabul edilip edilmemesi bir şeyin ortaya çkma sürecine bağlı olmaktan öte toplumsal içindeki yerine ve bağlamına oturtulmalıdır (Kejanlığlu 2005, s.175). Teknolojilere ve teknoloji ürünlerine aşırı önem verilmesi konunun arka planındaki düşüncenin gizlenmesini beraberinde getirmektedir. Adorno'ya göre üretim ilişkileri, üretim araçlarına gösterilen soyut göndermelerle gizlenmektedir (Bloch vd. 2018, s.172). Teknolojinin arka planının soyutlaştırılması anlamın değer kaybetmesine yol açmaktadır.

Düşünür'e göre aklın özeleştirisi ahlaklar içerisinde en muteber olanıdır. Akıl, özeleştirisini yapmiyorsa nihayetinde varılacak şey düşüncenin kıymetsiz hale gelmesi ve öznenin ortadan kaybolmasıdır (Adorno 2017(a), s.132). Adorno'ya göre teknoloji bireylerin aktif yönlerini devre dışı bırakmakta, aklı ve düşünceyi gereksiz kılmakta, kişileri aynileştirerek atomize etmekte/şeyleştirmekte ve hegemon sınıfın çıkarlarına uygun hale getirmektedir. Adorno için her şeyleştirme bir unutturma demektir (Jay 2014, s.411). Modern toplum ve yapı biçimleri teknolojiyi başarılı bir biçimde kullanarak insanları baskı halinde tutmakta, bireysel akıl bastırılmakta ve insanlar sistemin istediği formata sokulmaktadır (Kızılçelik 2000, s.185). Kapitalist sistem, eleştirinin yok olduğu ve öznenin ortadan kaybolduğu bir aklı egemen kılmıştır. Adorno'nun sistem karşıtı ahlak çağrısı sadece ötekinin var olmasına izin vermeyi değil ayn zamanda ötekinin konuşmasını, eleştirmesini ve temsilininim kabulünü gerektirmektedir (Morris 2001, s.38).

Kitle kültüründe ilerleme ile gerilemenin eşdeğer olduğunu ispatlayan göstergelerin en önemlisi teknik imkânlar nosyonudur. Mekanik yeniden üretim süreçleri yeniden imal ettiği şeylerden bağımsız hale gelerek özerkleşmiş ve bu durum başlı başına bir kültür görünümü kazanmıştır (Adorno 
2017(a), s.124). Teknik ilerleme kültüründe bir şeyi satın alma ve mutlak anlamda üretim sürecine katılma, bir ideolojidir. Bu ideoloji bireyin tüm yaşantısına etki eder durumdadır. Kültür endüstrisinde sistem oluşturmuş olduğu kültüre doyumu yasaklamıştır.

"Her program sonuna kadar dinlenecek, bütün çok-satarlar okunacak, her film daha Odeon galasında izlenecektir. Ayrımsızca tüketilen metaların bolluğu büsbütün zararlı ve yıkıcı bir boyuta ulaşmıştır bugün. Kişinin kendi yolunu bulması imkânsızlaşmaktadır ve tıpkı devasa bir markette kılavuz arayan adam gibi, mallar arasına sıkışmış nüfus da liderini beklemektedir" (Adorno 2017(a), s.125)

Adorno'ya göre teknolojide araçların fetişleştirilerek amaç haline getirilmesi bir saçmalıktır (Adorno 2016, s.316). Kültür endüstrisinde teknik terimler kullanılarak sistemin toplum üzerinde oluşturduğu güç ve sistemin asıl amacı geçiştirilmeye çalışılmaktadır. Teknik rasyonalite hegemonyanın mantığının sürdürülmesinde oldukça önemlidir. $\mathrm{Bu}$ rasyonalitede bilince müsaade edilmemekte; kendisine ve topluma yabanclaşmış insanların varlığı önem kazanmakta ve anlama ilişkin bütün değerler geçersiz kılınmaktadır (Adorno ve Horkheimer 2014, s.163-167). Sistem herkesin uyması gereken bir bilinç, imge ve düşünme biçimi oluşturarak bunu yaygınlaştırmanın en kolay yolunu aramakta; bu bilinç, imge ve düşünce ile karşılaşan bireyler sistem göstergelerine uygun davranmakta ve böylelikle kültür endüstrisi kültürel seri üretimini gerçekleştirmektedir. Bu endüstrinin gelişmesinde kitle iletişim araçları ve bu yapıların teknik unsurları (efekt, ses, müzik, kurgu gibi) durmaksızın çalıştırılmaktadır.

“Bütün dünya kültür endüstrisinin süzgecinden geçirilir. Film, gündelik algı dünyasını yeniden vermeyi amaçladığı için, dışarıdaki sokakları az önce izlediği filmin devamı olarak algılayan sinema izleyicisinin bu bildik deneyimi yapımın temel ilkesi haline gelmiştir" (Adorno ve Horkheimer 2014, s.169).

Adorno sanatın teknik olarak yeniden üretilebilir olması neticesinde auranın kaybolduğunu düşünmektedir. Adorno teknolojik olarak yeniden üretilen sanatın negatif boyutunun yanı sıra özerk sanatın pozitif yönünün de göz önünde bulundurulmasının gerekliliğini vurgulamıştır (Kejanlığlu 2005, s.172). Adorno sanatta angajman olamayacağını iddia ederek angaje sanatın çeşitli olumsuzluklar yaratacağını düşünmektedir. Ona göre üstlenmek bir şeye mutlak bağımlılık anlamı taşımaktadır (Kula 2013, s.293). 
Angaje sanatların yerine özerk sanatlara yoğunlaşarak değer çizgilerinin belirlenmesi gerekmektedir. Zaten büyük sanat yapıtları incelendiğinde bu yapıtların özerk oldukları ve en sorunlu anlarda bile başarılı oldukları görülmektedir. Bunun olabilmesi için bu eserlerin dizgeye mugayir anlam oluşturmaları yani teknoloji bağlamından kopartılmaları gerekmektedir. Adorno, teknik sanat ve endüstriyel teknoloji arasındaki ilişki bağlamında endüstriyel teknik akılla mücadelede alternatif yöntemlerin gerekli olduğunu düşünmektedir(Hansen 2012, s.213)

Teknolojik gelişmelerle birlikte seri üretim meydana gelmiş ve sanat yapitlarının aurası yok olmuştur. Bu yok oluş sadece sanat eserinin özgünlügünü yok etmemiş aynı zamanda geleneğe dayalı deneyimi de yıkmıştır. Sistemin belirlediği kitle toplumunun mevcut kültürel durumu artık ritüelden bağımsız hale gelerek politikleşmiştir. Teknik olanaklarla eserin yeniden üretilmesi-yani seri üretim- o eserin kült değerini yok etmektedir. Kült değeri yok olan bir eser sadece sergileme değeriyle sisteme hizmet edebilir ki bunun en iyi örneği sinema filmleridir (Jay 2014, s.334). Sinema filmleri teknolojinin kolaylıklarıyla seri halde çoğaltılabilmekte ve bu filmleri izleyen seyirciler statükonun belirlediği kodları kabullenmektedir.

Sanatın feodal anlayışa karşı üstünlügü kültür endüstrisi ile son bulmuştur. Sanat artık eleştirel yeteneğini kaybetmiş; toplumsal bilince olan katk1sını yitirmiş ve teknolojiyle yakın ilişki içerisine girmiştir. Kültür endüstrisine mahkûm kılınan sanat tekelci kapitalist anlayışa destek sunmaktadır ve yine sanat kitle kültürünün parçası haline gelmiştir. Burada kitle kültürünü bağımsız bir kültür olarak değil kapitalizmin hizmetindeki baskın güç olarak ele almak gereklidir (Slater 1998, s.232). Adorno'ya göre sanatın biçimsel bir niteliğe büründürülmesi ve biçime değer kazandırılması pozitivist ahlakın gerekliliğidi. Pozitivist ahlak sanatın özgünlügünü yok ederek imge ile bağını kaldırmıştır. Dolayısıyla düşünceden bağı kopartılan bütün biçimlere mesafeli davranmamız gerektiği gibi sanata da mesafeli davranmamı gerekmektedir. Adorno'ya göre ahlak felsefesi, kültürün insanlığın bütünü için doğru bir yaşam tarzı sunup sunmadığını sorgulatmalı, sanatın ahlaki tarafını ortaya koymalı ve yine aynı mantıkta kültürün insanlığın bütünü için doğru bir yaşamın ortaya çıkmasını engelleyip engellemediğini düşündürtmelidir (Adorno 2012(a), s. 23).

Birey, diğer bütün kişisel üretim yöntemlerinde olduğu gibi teknik gelişmelerin arkasında kalarak sistemsel aklın izleğini sürmüştür. Sistem nes- 
nelliği kendi himayesine aldığı için hakikate ilişkin arayışların bireyde aranması en doğru tercihtir. Kültür endüstrisini genel geçer kılan meşru otorite nesnelliği himayesine aldığı için hakikatin ve gerçekliğin izini öznel olanda yani bireyde bulmak gerekmektedir. Söz dinlemeyen ve kendi gerçekliğini mutlak kılan ilerleme insanlığın genel ilerlemesiyle oluşabilecek özdeşlikten bağımsız bir şekilde sürmektedir. Sistemin ilerleme hakikatine karşı oluşturulacak antitez ancak bireysel hakikatle gerçekleşebilir (Adorno 2017(a), s.136). Bireysel hakikatlerin evrensel hakikatlerle uyumlu hale gelmesi yani eşdeğer fayda tüm insanlık kurtulduğunda değer kazanabilecektir.

\section{Kültür Endüstrisi Hegemonya İlişkisi}

Kültür endüstrisinde hegemonya söz konusudur. Yani hükmedenler hükmedilenlere zorbalık veya şiddet uygulayarak egemenlik kurmamakta; aklın geliştirilmiş biçiminde kendiliğinden oluşan bir egemenlik ortaya çımaktadır. Hükmedenlerin zaman zaman kendi düşüncelerini gerçekleştirmek için uyguladıkları metotlar nesnel zorunluluk olarak ifade edilmekte ancak hükmedenler nesnel zorunluluk kavramına katiyen inanmamaktadır (Adorno ve Horkheimer 2014, s.61). Sadece hükmedilenler yaşam standartlarını etkileyen ve kendilerini aciz kılan değişimleri kaçınılmaz bir zorunluluk olarak görmektedir

Otoriter kültür endüstrisinin insanlara yüklediği görev ve sorumlulukların yerine getirilmesi sadece sistemi ilerletmekte; diğer yandan insanlı̆̆ geri döndürülemez bir felakete sürüklemektedir. Kitle kültürü insanlı̆̆ felakete sürüklerken zoraki yol ve yöntemlere başvurmamakta; insanlar gönüllü olarak bu felakete yoldaşlık etmektedir. Yani tahakküm dayandığı fiziksel şiddetten bağımsız hale gelerek insanlık üzerinde hegemonya kurmaktadır (Adorno 2017(a), s.190). Hegemonyanın hükmedilenlerce yayılması ve resmiyet kazanması üretim araçlarının kontrolünün öznel akıl tarafından yürütüldüğünün ispatıdır. Dünyadaki teknolojik gelişmelerin tamamında övgü, öznel akla yapılmaktadır. Basit egemen yöntemleri bırakan kitle kültürü teknolojiyi ve kitle iletişim araçlarını himayesine alarak hegemonya oluşturmasını bilmiştir. Hegemonik kültürde daha etkili ve kurnaz biçimde insanlar köleleştirilebilmektedir (Jay 2014, s.342). Üstelik insanlar egemenlikteki zoraki kölelikten bağımsız şekilde isteyerek köle olmayı tercih etmek- 
tedir. Tikelin ve evrenselin ortaklaşa faydasına katkı sunacak dünya giderek yok olmakta, bireyler pasif kurbanlar olarak sisteme hizmet etmekte, direnen güçler ise etkilerini kaybetmektedir.

Kültür endüstrisi hegemonyasını sürdürmek için sürekli ve yoğun politikalara ihtiyaç duymamaktadır. Çünkü insanlar hegemonyanın sürdürülmesinde politik değerlendirmelere gerek duymadan otomatikleşmişlerdir. Kişiler her ne kadar perişan olsalar bile sistemin sürekliliğinin devam edebilmesi için canla başla mücadele ara vermeden sürmelidir. Mevcut sistem çarkı kusursuzlaştıkça bireysel etkiler toplumsal etkiye dönüşerek evrenselleşmektedir. Kültür endüstrisinin çarkı insanları bütünün bir parçası kılmakta, ayn hale getirmekte ve kültür yeniden üretilmektedir. Kültür endüstrisinin neferleri zoraki bir egemenliğe başvurmayan sistemin buyruklarını ve bu sistemin zihin pratiklerini genişletmek için tetikte beklemektedir (Adorno ve Horkheimer 2014, s. 171).

Üst akıl hegemonyasını sürdürmek için artık kendini gizlememektedir. Çünkü gönüllü efendi köle ilişkisi kültür endüstrisinde durmadan işleyen bir mekanizmadır. Radyo, televizyon ve sinema artık sanatmış gibi davranmamakta doğrudan iş alanının ahlak düzlemine göre yayın yapmaktadır (Kejanlığlu 2005, s.185). Boyunduruk altına alınanlar ise boyunduruk altına alınmalarını kutlamaktadır (Adorno ve Horkheimer 2014, s.380).

Seri üretim kültürü ve sayısız neden aracllığıyla kural haline getirilen davranış biçimleri kişilere tartışmasız doğal, saygıdeğer ve makul olarak dayatılmaktadır (Adorno ve Horkheimer 2014, s.49-50). Kişiler bu davranış biçimlerine uyum ve uyumsuzluk göstererek istatiksel anlamda + veya değer kazanmaktadır. Bireyin yerine getirmesi gereken davranışlar ve sisteme uyum, kültür endüstrisinin belirlediği başat kalıplar tarafından sistematize edilmiştir. Öğretinin belirlemiş olduğu normların haricindeki fikir ve davranış eğilimleri çeşitli kolektif yapılar tarafından kontrol altında tutulmaktadır. Bu kontrolün her zaman için görünür faaliyetlerle olmasına gerek yoktur. Çünkü anlam değişikliğine uğratılan kültür insanların düşünceleri ve fikirleri üzerinde de etkili olmaktadır. Kontrolün görünür faaliyetler ve kültür üzerinden hegemon kılınmasında perde arkasındaki güç ve kolektif davranış biçimlerini emreden erk sahipleri, dünyayı istedikleri biçimde yönetebilmektedir.

Kültür endüstrisinin kişileri hegemonyasına almasında etkili olan kitle iletişim araçları Adorno tarafından eleştirilmiştir. Bu araçlar artık ticari bir 
formata girmiş ve değersizlikleri yasal duruma getiren bir ideolojiye dönüşmüştür (Kızılçelik 2000, s. 231). Kitle iletişim araçları sıradan bir işten başka bir şey olmadıkları gerçekliğinde sistem ideolojisini yaymayı sürdürmektedir. Gerçekliği, anlamı ve amacı sistem tarafından değiştirilen bütün alanlar yörüngeleri dışında oyun oynamaya devam etmektedir. Sistem bu alanların anlamını ve işlevini kendi bilincine devşirmiştir. Örneğin sinema ve radyonun artık sanat olma iddiasında bulunmasina gerek duyulmamaktadır (Adorno ve Horkheimer 2014, s.163).

\section{Kültür Endüstrisi İletişim Araçları İlişkisi}

1930'lu yıllara kadar kültür endüstrisinin kitle iletişim araçlarıyla ilişkisi henüz kuramsal bir temele oturtulmamıştı. Ancak Frankfurt Okulu teorisyenlerinin ve Adorno'nun Amerika'ya zorunlu göçü neticesinde kültür endüstrisi teorisi somut bir anlam kazanabilmiş ve bu endüstrinin kitle iletişim araçlarıyla ilişkisi daha başarılı biçimde gözlemlenebilmiştir.

“Eleştirel teori savunucuları 1930'larda Amerika'ya göç edinceye değin üzerinde çalışmalarına karşın henüz 'kültür endüstrisi teorisi' geliştirememişlerdir. Eleştirel Teorisyenler Amerika' da iken [sürgün dönemi], tüketim toplumunun doğuşuna, kitle kültürü ve iletişimin çoğalmasına, Amerikan başkanının [Roosevelt'in] politik iknalar için radyoyu kullanmasına, her tarafta binlerce Amerikalının sinemaya ve tiyatroya gidişlerine tanık olmuşlardır. Aynı zamanda Frankfurtçular magazin, komik kitaplar, seks dergileri....yeni kitlenin ürettiği kültürün ürünlerini, ucuz kurguların genişleyen popülaritesini gözlemleme olanağı bulmuşlardır. Özellikle de California'da Horkheimer ve Adorno iş çevrelerinin/zengin kesimlerin kitle kültürünü nasıl egemenlikleri altına aldıklarını, medya ve tüketim toplumunun ortaya çıkması için eğlence endüstrisinin nasıl çaba sarf ettiklerini gözlemlemişlerdir" (Kızılçelik 2000, s. 220).

Adorno gerçek anlamda özgürleşme ve bireyleşmenin imkânsızlığı atomlaşma kavramıyla ifade etmektedir. Atomlaşma kavramı özdeşlik mantığından uzakta sadece bireyin diğer bireylerden uzaklaşmasını değil bireyin kendi içerisinde bölünmesini ve hayatının çeşitli alanları arasına sınır koyan tutarsızlığı da ifade etmektedir (Adorno,2017(a), s.137). Zaten baskıcı toplumlarda özgürlük; boş lakırdı, gerçekliği olmayan bir durum ve kültür endüstrisinin uydurmasıdır. Bireyler atomize edildikten sonra ortaya çıan 
ilişkiler sadece soyutlamalardan ibaret hale gelmekte ve gerçek değerdeki yüz yüze iletişimler gerçekleşmemektedir. İnsan ilişkileri ve iletişim araçları öznel aklın himayesine girdiğinden dolayı özgürlükler sadece soyutlanan özellikleriyle geçerli durumdadır.

Adorno kültür endüstrisi nosyonunu popüler kültür ve kitle kültürü kavramları yerine kullanmıştır. Gerçekte bu üç olgu aynı bağlama işaret etmektedir. Kitle kültürü yapay, kanalize edilebilen, şeyleştirilmiş ve gerçek olmayan bir kültürdür. Kitle kültürünün oluşmasında araç olarak kullanılan kitle iletişim araçları sadece topluma ve bireylere bilgi ve haber ulaştırmamakta; aynı paralelde sistemin faydasına uygun şekilde bireysel ve toplumsal yaşamı düzenleyen düşünce yönetimine uğraşmaktadır (Witkin 2003, s.50-60).

Genelinde bütün insanlar özelinde ise tekil bireyler önceden olduğu gibi şimdilerde de efsunlanmış haldeler. İnsanların onları olumsuzlayan şeye dönüşmesi ve bu dönüşüm ideolojisinin içselleştirilmesi salt efsunla gerçekleşebilmektedir. Nominalist ilke efsunlaşmış insanları bireyselleşmiş gibi gösterse de kolektif bir toplumsal anlayışın sürdürülmesi söz konusudur. Genel uğruna kendinden ödün veren çarpitılmış tikel unsur, çarpitılmış genel unsura hizmet etmektedir. Efsunlaşıp şeyleşen bilinç bütünlüğe evirilmektedir (Adorno 2016, s.313). Akıllı bireylerin sağ kalabilmek için riayet ettikleri gerçeklik insanları efsunlamıştır. Bu efsunun gizlediklerini ortaya çıkarabilecek herhangi bir arzu ve istek yoktur. Kötüsü insanlar gerçekliğin bu efsun olduğunu düşünmekteler. Efsunun insanlar arasındaki dolaşımında yani iletişimde kültür endüstrisi gerçeği gizli bir çaba göstermektedir.

"Günümüzde iletişim adıyla anılan istisnasız her şey, efsunun etkisi altında tutulanların suskunluğunu bastıran gürültüdür. Tekil bireylerin kendiliğinden edim ve eylemleri, muhalif olduğu varsayılanlar da dâhil olmak üzere, birer sahte aktiviteye, potansiyel bir eblehliğe mahkûmdur. Dışarıdan uygulanan bir beyin yıkama ve benzeri tekniklerde, yine dışarıdan teşvik edilen bir içkin-antropolojik eğilim iş başındadır" (Adorno 2016, s.315).

Adorno efsun ve ideolojinin ayn şey olduğunu düşünmektedir. İdeoloji ve efsun, sürekli genel üzerinden dolayımlanıp birey psikolojisini içerisine alan ve geneli tekil bireylerde mütamadiyen üreten bir kap olarak değerlendirilmektedir (Adorno 2016, s.315). İdeoloji haline getirilen efsun bütün kitle iletişim araçlarında kendini göstermektedir. 
Adorno kültür endüstrisi eleştirisi yaparken kültür endüstrisinin eğlence kurumları oluşturmasına da değinmiştir. Ona göre kültür endüstrisi denilen şey kitle iletişim araçlarında oluşturulan eğlence sanayidir (Kızılçelik 2000, s.233). Aclanı ve düşünmeyi görmezden gelmeye katkı sağlayan bu araçlar insanları aciz hale getirmekte ve böylelikle kapitalist sisteme katma değer sağlamaktadır. Eğlence yoluyla sistemin sorgulanmasının önüne geçilmekte ve gerçek meselelerden uzaklaşılmaktadır.

İşsizler eğlence tuzağına en fazla düşenlerdir. Bu insanlar sıcaklığı ayartılmış sinemalarda kışın ısınmakta yazın ise serinlemektedir. Kitle kültürü ve buna bağlı olarak ortaya çıkan eğlence planlaması hoşnutsuzluğu ortadan kaldırmak maksatlı üretilmektedir. Ancak bu türden üretimler asla gerçek bireysel mutluluğu insanlara sunmamaktadır. Kültür endüstrisi sistemin devamlılığında eğlenceyi bir araç olarak kullanmaktadır. Bu endüstride eğlenmek hemfikir olunduğunu yani sisteme uyum gösterildiğini ispatlamaktadır. Eğlenebilmek düşünememenin somut göstergesidir (Adorno ve Horkheimer 2014, s.193). Adorno düşünememeyi acizlik olarak değerlendirmektedir. İnsanlığın kurtuluşu olabilecek son direniş düşüncesi bile yok olmuştur. Özgürleşmek zihinsel nitelikten koparak düşüncesizce eğlenmeye evirilmiştir. Düşüncesizliğin sürdürülmesinde kitle iletişim araçları durmaksızın yayın yapmak zorundadır. Kültür endüstrisi akıl ile eğlenceyi birbirinden ayırmamaktadır. Aydınlanma projesi bu bakımdan akıl, mit ve eğlenceyi ayn potada eritmektedir (Wilson 2007, s.27).

Teknik ve sosyal ayrımlaşma ile birlikte kültürel bir karışıklığın meydana geleceği görüşü geçerliliğini kaybetmiştir (Adorno ve Horkheimer 2014, s.162). Mevcut haliyle kültür her şeye temas etmesini bilmiştir. Kitle iletişim araçları sistemin belirlediği kültürü yayabilmek için mütemadiyen çalışmakta ve sözbirliği etmişçesine aynı ağız birliğiyle kültürü kutsallaştırmaktadır. Siyasetin kendi muhalif anlayışı bile kültür söz konusu olduğunda ortak anlaysşla kültürün övgüsünü sürdürmektedir.

Adorno'ya göre fotoğraf gerçekliğin ortaya çıkmasından sinemaya nazaran daha güvenilir bir aygittır (Adorno 2017(a), s.151). Çünkü anlama müdahalenin kurgusallığı fotoğrafta daha azdır. Sinema anlamlı olay örgülerinin yer aldığı romanları yeniden işleyerek asalakça yağmalamakta, tutarlı anlamı paramparça etmektedir (Adorno 2017(a), s.151). Sistem ideolojisinin sinema tarafından işletilmesi gerçekliğin ve anlamın değerini ortadan kaldırmaktadır. Adorno'ya göre kültür endüstrisinin yeniden üretiminde si- 
nema filmleri oldukça önemlidir. Seyirci eleştirel olmayan bir şekilde filmleri izlemektedir. Bu durum kültür endüstrisinin sinemayı sömürü aracı olarak kullandığının ve bu endüstrinin başlı başına bir ideoloji olduğunun ispatıdır (Fraser 2018, s.21).

\section{Kitle İletişim Araçlarnnın Bireyleri Standartlaştırması}

Kültür endüstrisi bireylerdeki farklılıklar yok ederek insanları birbirine benzetme derdine düşmüştür (Huhn 2006, s.263). Bundaki amaç benzeşen insanların kontrolünün daha kolay olmasıdır. Kültürü himayesine alan sistem, kültürün alt bileşenleri spor, kültür, sanat, medya ve estetiği de ele geçirerek istediği biçimde kullanabilmektedir. Örneğin radyo dinleyicisi müziği eleştirel işlevinden bağımsız biçimde, gayrı şahsi hale getirilmiş formatta, kolektif ve şeyleştirilmiş bir şekilde dinlemektedir (Jay 2014, s.304). Müziğin arka planındaki ideoloji, yeniden üretimle toplumun ideolojisi haline getirilmiştir. Müzik ideolojisi gerçekte burjuva anlayışının eğitim ve kültür alanında kabul gören yeniden üretiminden başka bir şey değildir. Radyo, kültür endüstrisinin yeniden üretiminde ideolojiyi müzik görünümünde alıcılara aktarmaktadır. Makineleşme atlı arabaları nasıl ortadan kaldırıyorsa aynı şekilde radyo da gerçek müziği ortadan kaldırmıştır. Radyo onaylanmış eğitim ve kültürü müzik biçiminde insanlara aktarırken dikkati bozacak şekilde yayın yapmalı ve bireylerin atomlaşmasını güçlendirmelidir (Adorno 2018, s.80). İnsanların gerçek meselelerden uzaklaşmasına yardımcı olan radyo, arkasında var olan sistemin güçlenmesine katkı sunabilecek tahakküm biçimlerinin gelişmesine siyasal anlamda da fayda sağlamaktadır. Adorno'nun radyo analizi kapitalist düzenin eleştirisine ve bu düzende kültür endüstrisinin toplumsal yapıda meydana getirdiği değişiklikler üzerine odaklanmış; böylelikle kişilerin pasifize edilmesini ele almıştır (Benzer 2011, s.231).

Radyo dinleyicisi için müziğin mevcudiyeti yok olmakta ve müziğin aurasına ilişkin tılsım kaybolmaktadır (Jay 2014, s.305). Bireyi yaşadığı toplumdan izole eden radyo, zaman ve mekân bilincini yok etmekte; kolektif iletişim becerilerinden mahrum bırakmakta; atomize edilmiş bireyler üreterek standartlaşmaya teşvik etmektedir. Ayrıca radyodan duyulan müzik sanki kültürel kaynaklarla üretilen bir şeymiş gibi gösterilmekte gerçekte ise müziğin sosyal-psikolojik arka planında sistemin endüstri haline getirdiği 
bir anlayış işlemektedir. Sistem insanlardan otoriter itaatin ürettiği kitle iletişim araçları mesajlarına uyumlamalarını beklemektedir. Adorno için otoriter itaat; yaşanılan toplumda sistemin idealize ettiği ahlaki ve kültürel kodlara tabi olmak ve her ne olursa olsun sistemi eleştirmemek demektir (Jay 2014, s.377).

Adorno'ya göre kitle iletişim araçlarının demokratikleşmeye katkı sağladığı söylemi bilinçli bir şekilde insanlara aktarılmaktadır. Bu araçların demokratik olması demek bütün alıcıların dinleyiciye dönüşmesi ve hep aynı programları izlenmesi/dinlemesi anlamına gelmektedir. Örneğin radyo yayınlarının yaptığı şey sistemin belirlediği aynılıkları dinleyiciye aktarmaktır. Demokratikmiş izlenimi verilen kitle iletişim araçları aynı olma durumunu farklılık ve özgürlük söylemiyle sunmaktadır (Kejanlıŏlu 2005, s.186). Modern toplumun kişileri iletişim araçları aracılığıyla hegemonyaya mahkûm kılınmıştır. Kültür endüstrisini yayan bu araçlar ile kişiler oyalanmakta ve pasif hale getirilmektedir. Adorno özelde radyoyu ve genelinde kitle iletişim araçlarını faşizme uyumlu kültür ideolojisi dağıtıcısı olarak görmektedir (Slater 1998, s.236).

Adorno için sinema filmleri insanları aptallaştıran ve kötüleştiren kitle iletişim arac ürünleridir (Adorno 2017(a), s.28). Sinema, insanlara özgür olduklarını inandırmanın bir aracıdır. Adorno'ya göre kitleler sinema filmleri aracılığıyla gerçeklere yabancılaştırılmaktadır. Bireyler daha fazla film izleyerek özgür olduklarına inandırılmakta ve gerçekte ise dizgenin kurallarına uyum sağlanmaktadır. Kitle toplumunda özgürleştirilmiş birey söylemi sadece ütopik nitelikler taşır. Sinemanın gerçekte yaptığı şey kişilerin acı çektiğinin gizlemesidir (Wall, 2013, s.4). Gerçek anlamda özgürleşme ve bireyselleşme şu an mümkün gözükmemektedir. Adorno'ya göre sinema seyircisinin kahkahalarında güzel olan veya devrime olanak sağlayan hiçbir şey yoktur; tersine bu kahkahalar burjuvazinin yüceltilmesinden başka bir şey değildir (Adorno 2012(b), s.128). Sinemada nitelikli öğelerin hiçbirisi seyirci dikkatini çekebilecek anlamı göstermemektedir. Kültür endüstrisi dışarıda herhangi bir öğe kalmayacak şekilde bütün öğeleri birbirine bağlamış ve sinemayı bu anlamda etkili biçimde kullanmıştır (Adorno 2017(a), s.215). Mevcut haliyle karşı sav olarak ifade edilebilecek herhangi bir güç şimdilik gözükmemektedir.

Sinema filmleri mütemadiyen artan bir şiddetle seyirciyi kendisine bağımlı kılmaktadır (Kejanlığlu 2005, s.187). Bu bağımlılık insanların bütün- 
leşik anlamda tek tipleştirilmesine yol açmaktadır. Adorno, bütünleşik hale getirilen kitle iletişim araçlarının bireyleri de bütünleştirerek uyumlu hale getirdiğini düşünmektedir. Dirençten bağımsız hale getirilen bütünleşik insanların dönüşme/düşünme yolları kapanmakta ve eğlence ile insanlar kendilerinden geçmektedir.

Film ve kültür endüstrisine bağlı diğer bileşenler bütünleşik bir biçimde sisteme bağllı̆̆ı ve düşünememeyi otomatik bir alışkanlık haline getirmektedir. Sinema film hakkında yapılan bütün yorumlar üst akla itaat ettirmek amacıyla yapılmaktadır. Her türlü kurgu herhangi bir itiraza mahal bırakmayacak biçimde seyirciye sunulmaktadır (Adorno 2018, s. 91). Oyunun kuralında sorgulamadan itaat ettirebilmek baskın bir biçimde hissedilmektedir. Anlamdan yoksun kılınan kodların sinemada seyircilere aktarılması insanların düşünmemeleri isteyen bir buyruktur (Adorno 2017(a), s.213). Toplumsal yaşamin bütün alanlarına etki eden sinema ideolojisi gerçekte insanların nesnel çıkarlarıyla uyuşmamakta sadece hizmetin sürdürülebilir politikalarına yardımcı olmaktadır (Miklitsch 2006, s.8-15). Sinema özellikle kitle kültürünün devam ederek kültür endüstrisinin devamlılığında önemli bir araç konumundadır.

Kültür endüstrisi, kitlesel olarak tüketilen sinemayı popüler bir sanat olarak tanımlamaktadır (Adorno 2017(a), s.211). Gerçekte filmlere sanat payesi kazandırmak ortaya çıkan ürünü sahteleştirmek demektir. Sinema bir kitle sanatı değildir; kitleleri sisteme kanalize edebilmek için kullanılan bir araçtır. Sistemin kolektif üretiminin en önemli yardımcısı kolektif izlemeye olanak sağlayan sinema filmlerdir. Filmler kitle kültürüne ait olan zevk ve beğenileri insanlara kabul ettirmektedir. Zaten kitle kültürünün belirlediği zevk ve beğeniler haricinde bireylerin alternatif zevk ve beğenileri söz konusu değildir.

Adorno için filmler kültürel mirasın sonraki kuşaklara aktarılmasını sağlayan araçlardır (Adorno 2018, s.227). Bu araçlar büyük kitlelere aynı anda mesaj aktarabilme kapasitesine sahip olan ve böylelikle kültürel endüstriyi yaygın kitlelere ulaştıran medyumlardır. Modern kültür endüstrisiyle niteliği dönüştürülen filmler; sadece yaşanılan dönemde değil sonraki zaman dilimlerinde de tüketim ürününe dönüşen bireylerin atomize hale gelmelerine yol açmakta ve böylelikle bilinçlenmenin önüne geçmektedir.

İnsanlar ve insani niteliğe sahip olan şeyler kusursuz biçimde eşyaya indirgenmiş ve insanla şey arasındaki farklar belirsizleşmiştir (Adorno 
2017(a), s.214). Sinema bireyleri istenilen formatlara dönüştürmede fazlasiyla başarılı olmuştur; bireylerin artık düşünsel gelişmelere sahip olması imkânsızlaşmıştır. İnsanlar kendi insan dışlıklarını sinemada rahatlıkla izleyebilmekte ve bunu insancl gösterimler şekliyle anlamaktadır. Filmler belirli duyguların taklit edilmesine neden olmaktadır. Kaygı, özlem, erotik bakış, şehvet vb. temsili için belirli fizyonomik örüntüler filmlerde seyir edildikten sonra izleyiciler tarafindan taklit edilmektedir (Adorno 2018, s.169). Ancak bu taklitler gerçek duygu niteliği taşımamaktadır. Adorno, bu duyguların taklit duygular olduğunu ve insanlar üzerinde iletişim etkisi oluş̧urmayacağını düşünmektedir.

Kültür endüstrisinde güzel olan şeyler kameranın yeniden ürettiği görüntülerdir (Adorno ve Horkheimer 2014, s.197). Yakın çekimler ile elde edilen şey görsel şeylere hayranlıkla bakılmaktadır. Ancak hayran olunan şeyin arka planında neyin gizlendiği dikkate alınmamaktadır.

"Filmde psikolojik bir yazgının hangi zorlukları yansitılırsa yansitılsın, tüm olan biten beyaz şeridin üzerinden izleyicinin gözü önünde akıp gittiği için, karşıtlıkların gücü ve barındırdıkları özgürlük olanağı kırılır ve önce ile sonranın soyut zaman ilişkisinde aynı düzeye getirilir. Çatışmayı izleyiciden önce görüp, hiçbir direnç göstermeden akıp giden film şeridine yans1tan kameranın gözü, çatışmaların çatışma olmaması için gerekli önlemleri alır. İmgelerin teker teker, fotoğrafı kaydedilen hareketin kesintisiz art ardalığında beyaz perdede sürüklenmesi onları baştan salt birer nesne yapar" (Adorno ve Horkheimer 2014, s.358)

\section{İmgenin Değersizleştirilmesinde Kitle İletişim Araçlarının İşlevi}

Filmler sesli hale getirilerek yaşama etki eder kılınmakta; böylelikle izleyicinin hayal gücü ve düşüncesi filmin sunduğu çerçeve içinde kalmaktadır. Sessiz film döneminde yazı ve imaj birbirini tamamlayan ve birbirlerinin yerine geçen şeydi (Adorno ve Horkheimer 2014, s.386). Sessiz filmlerde kişi ses yönlendirmelerinden bağımsız şekilde imgesine etki eden görselleri bilince dönüştürebilmekteydi. Şöyle ki görüntü mesajin önüne geçemeyen salt arka plan unsuru olarak değerlendirilmekteydi (Adorno 2018, s.142). Ancak sesli filmler sistemin belirlediği olgusal kavramlar çerçevesinde izleyicinin düşünsel faaliyetlerine müsaade etmektedir (Adorno ve Horkheimer 2014, s.170). 
Kültür endüstrisinin oluşturmuş olduğu sahte gerçeklik ile bilinçaltı formlarının oluşturulmasına ihtiyaç kalmamıştır. Bundan böyle sinema kurgusal anlamda kültür endüstrisinin ideolojisini oluştururken yan anlamlara ve gizli mesajlara ihtiyaç duymamaktadır. Sinema konformist mantığ imal ederken somut ve görünen anlam neyi ifade ediyorsa onu doğrudan işleyebilmektedir (Adorno 2017(a), s.148-149). Sinemanın imgeye etki eden anlamı kültür endüstrisi tarafından durmaksızın işletilmektedir.

Sistemsel kültürü oluşturan mikrokozmos ile sistemsel kültürü benimseyen makrokozmos özge bilinçlerinden vazgeçerek özdeş hale getirilen kültürü yani kitle kültürünü devam ettirebilmek için muazzam derecede çaba göstermektedir. Sistemin işleyişiyle ilgili yönetimi elinde tutan sistem yürütücüleri sistem kültürünün asıl amacını gizleme hususunda artık tedirgin değildir (Adorno ve Horkheimer 2014, s.162-163). Sistem imgeye etki edecek gerçekliği ele geçirdiği için anlamı hangi yönde işleyeceğini gayet iyi bilmektedir. Örneğin sinemada akıl ile iletişim arasındaki dengeyi ortaya çıkaran belirginlik hem doğru hem de yanlıştır (Adorno 2017(a), s.149). Çünkü sistem görme alanında imgeye hangi anlamı yükleyeceğini hesaplamaktadır. Sinemada belirginliğin ve olayın hesaplı biçimde yapıldığı yani imgeye istenilen şekilde etki edilebilen gösterimlerde anlamlar yönlendirilebilmektedir.

Televizyondan gösterilen görüntülerin mutlak hızı ve durmaksızın devamlılığı imgeyi ve düşünceyi olanaksız kılmaktadır. Gözlerin kitap satırlarını takip etmesine benzer biçimde görüntü sadece izlenmekte lakin görüntünün ardışıklığı yüzünden bilinç devre dışı kalmaktadır. Televizyondan sunulan görüntülerin izlenmesi anlamın devre dışı bırakılarak sadece ekranın takip edilmesidir (Adorno 1954, s.213). Ekrandaki görüntüler mistik, analizi imkânsız ve belirsiz nitelik taşıyan imajlar değildir. Birazcık düşünmesini bilen insan televizyonun arka planındaki gücü ve mantığı çözebilecektir. Ancak düşünmek ve eleştirmek zahmet gerektiren işlere dönüşmüştür. İnsanlardan mütemadiyen çalışmalarının istenmesinin nedeni de düşünmeyle bağın kopartılması içindir. Bireyler mevcut üretim sistemine uygun biçimde hizmet edebilsinler diye toplumsal, ekonomik, ahlaki ve bilimsel olarak hazır kalıp hale getirilmişlerdir; kültür endüstrisinde sadece türsel varlık olarak yaşamaya mahkûm kılınan insanlar, hegemonya altında tutulmakta ve düşünceden uzak birakılmaktadır. (Adorno ve Horkheimer 2014, s.59-60). 


\section{Tüketim ve Kitle İletişim Araçları İlişkisi}

Reklam kültür endüstrisinin amentüsü, ana dili ve üslubudur. Reklam kültür endüstrisinin yaşam iksiridir (Adorno ve Horkheimer 2014, s.215). Reklam ve kültür endüstrisi hem ekonomik anlamda hem de teknolojik anlamda bütünleşik hale gelmişlerdir. Kültür endüstrisinin bireyler üzerindeki mutlak teknolojik etkisi Adorno tarafindan psiko teknoloji kavramıyla açıklanmaktadır (Kejanlığlu 2005, s.189). Psiko teknoloji kavramı kültür endüstrisi hizmetinde bulunan bütün teknolojik aygıtların ve kitle iletişim araçlarının insanların psikolojisi üzerindeki şeyleştirici ve atomize edici etkisi bağlamında ele alınmalıdır (Adorno 1991, s.158-159). Psiko teknoloji; kültür endüstrisinde tüketicilerin ürünlerin ne olduğu gerçeğini bilmelerine rağmen o ürünü satın almaya kendilerini mecbur hissetmeleri durumudur. $\mathrm{Bu}$ anlamda reklamlar, totaliter rejimlerde hangi kuruluşların açlıp hangilerinin kapatılacağını denetleyen kurullara benzemektedir.

(Adorno ve Horkheimer 2014, s.215).

Sistem himayesindeki reklam tüketiciye yol göstermekte, malların tanıt1lıp hızlıca tüketilmesini sağlamakta, alıcıya rehberlik etmekte ve hegemonyayı yeniden üretmektedir (Kızılçelik 2000, s.229). Sistem hegemonyasını aleni bir biçimde söylemektense reklamlar vasıtasıyla sürdürmektedir. Bu anlamda reklamlar ve kültür endüstrisi hem ekonomik hem de teknik anlamda tek bütün olmuşlardır. Adorno reklamların bireyleri belirgin olmayan şekilde baskı altına aldığını, hegemonya oluşturduğunu ve totaliteryanizme yol açtı̆̆ını düşünmektedir.

Tüketim mallarının bu denli fazla olduğu ve sürekli üretildiği bir ortamda insanların belirli mülkiyetlerle kısıtlandırılması işleyişi bozmaktadır. Sistem belirli süre aralıklarla mülkiyet edinilmesine müsaade etmekte ancak zamanı geldiğinde o mülkiyetin değiştirilmesini buyurmaktadır. Bu durumun arka planında sadece nesneleri sahiplenmeme ve nesnelere gösterilen sevgisizlik yer almamaktadır. Aynı şekilde insanlar da sahiplenilmemeli ve sevilmemelidir. Kitle kültüründe barbarlık ve ilerleme eşzamanlı olarak gelişmektedir (Adorno 2017(a), s.55). Mülkiyetin egemenliğinin ilerleyişi öznenin eleştirel gücünü yok etmiş ve hayal gücü imge ile bağlantısını kesmiştir.

Adorno kültür endüstrisinde sistem tarafından üretilen emtiaları salt kâr bağlamlı görmemekte; konunun arka planında mütemadiyen kendini üre- 
ten bir kapital ahlak ideolojisinin olduğuna inanmaktadır. Bu ahlak ideolojisinde reklamlara önemli görevler düşmektedir. Bireyselleştirilmiş standartlaşmanın üretimi ve dağıtımında reklamlar hayati önem taşımaktadır. Kitleler bireysel bağlamda dizgenin kendilerine istenilen her şeyi verdiğini zannetmektedir. Gerçekte ise ihtiyaçları ve doyumları belirleyen zaten sistemin kendisisidir. Sistem arka planda ihtiyaçlar belirleyerek kitle iletişim araçlarıyla dolaşıma sokmakta ve bu dolaşım sonucunda ortaya çıkan ürünler sanki bireyselmiş gibi değerlendirilmektedir.

Adorno televizyon programları incelemelerinde iki kavram üzerine yoğunlaşmıştır. Bunlar çok katlı yapı ve stereotipleştirmedir. Çok katlı yapı tüketicinin tuzağa düşürülmesi ve onun psikodinamik biçimde önceden belirlenmiş etkilerin hizmetine sürülmesi amacıyla sistemin çeşitli olasılıkları değerlendirerek şartları düzenlemesi; yani seyirciyle baş edebilmenin teknolojik bir yönü olarak kitle kültürünün dolaşımda tuttuğu farklı açıklık ve gizlilik derecelerini hesaba katmasıdır (Kejanlıŏlu 2005, s.195). Stereotipleştirme ise kitleyi daha kolay yönetebilmek için kitle iletişim araçlarının belirli kalıpları insanlara aktarması ve nesnel aklın öznel aklın buyruklarına uygun davranmasının sağlanmasıdır. Televizyon programları ekranda gözükür gözükmez önceden dinlenmiş bir müziğin belirtiselliğinde olduğu gibi izleyicinin vereceği tepki bellidir. Bu durum televizyonun insanları tek tipleştirdiğinin önemli bir ispatıdır. Televizyon izleyicisi neye maruz kalacağının farkında değildir. Maruz kalması durumunda uygun tepkiler üretecek teorik bilincin önemini gereksiz görmektedir.

\section{Sonuç}

Adorno'ya göre insan yaşantısının şeyleşmesi aslında yanlış bir ideolojinin başarısıdır. Eleştirinin görevi insanların şeyleşmesini sağlayan ideolojinin kültür endüstrisi içerisindeki etkisini ortaya çıkarmaktan ziyade kültür endüstrisinin arka planındaki esas bağlamı yani sistemin yeniden üreten aklı göstermek olmalıdır. Kültür endüstrisinin temelinde standartlaştırma fikri yatmaktadır. Kültür endüstrisine hizmet eden bütün teknolojiler (özellikle kitle iletişim araçları) insanları standartlaştırmak için kullanılmaktadır. Dizge insanları, eşyaları ve diğer her şeyi kategorize ederek verilere dönüştürmekte ve dönüşüm üzerinden standart kriterlerini belirlemektedir. Stan- 
dartlaşmada üst akıl genel aklı egemenliğine alarak yönetilmiş bireyciliği yeniden üretmektedir.

Kültür endüstrisi artık bir üslup halini almıştır ve bu üslup sisteme itaati emretmektedir (Adorno ve Horkheimer 2014, s.175). Kültür adı altında alt yapı ve üst yapı bileşenlerini bir araya getiren sistem mugayir zihinsel yaratıların engellenebilmesi için bütün tedbirleri önceden almaktadır. Adorno'ya göre ilerleme ve barbarlık kültür endüstrisinde öylesine iç içe geçmiştir ki mevcut kültür ve teknolojik araçlara karşı koyabilmek için barbarca bir perhiz gerekmektedir (Kejanlığlu 2005, s.57).

Kitle kültürü bireylere sunacağı bayağılığı üretmeden önce bireyin kendisini üretmektedir (Adorno 2017(a), s.155). Sinemaya, radyoya ve magazinlere durmaksızın saldıran bireyler üründen önce imal edilmiştir. Burada yumurta tavuk döngüsel sebep sonuç ilişkisi çözümlenmiştir. Sistem önce ürün imal ederek insanları bu ürünlere hazırlamamıştır. Önce insanlar ideolojik olarak hazır hale getirilmiş ve daha sonra ürünler imal edilmiştir.

Kavrama aygıtları algı gerçekleşmeden önce duyular üzerinde ideolojik etkisini oluşturmaktadır. İmgeler henüz üretim aşamasındayken daha sonra nasıl algılanmaları gerektiği hususunda anlama yetisi standartlarına göre belirlenmektedir ve kamusal yargı tarafından onaylandığını zanneden bilinç henüz gerçekleşmeden yargı tarafından şekillendirilmektedir (Adorno ve Horkheimer 2014, s.118-119). Daha oluşum aşamasındayken tehlikeyi sezinlemeyip durumun bu hale gelmesine göz yuman yaşlılar kültür endüstrisinin güçlenmesinin öncelikli suçlularıdır. Faşist düzenin iliklerine kadar ele geçirdiği ve çürüttüğü gençliğe hesap vermesi gereken yaşlılardır (Adorno 2017(a), s.155). Her türlü bilinçten ve değerden yoksun kalan gençlik güçlenen düzenle başa çıkabilecek yöntemleri yaşlılardan öğrenmemelidir.

Adorno kitle iletişim araçların aile ile olan iletişimi kesmesi bağlamında eleştirmiştir.

“Konuşacak bir şeyi olmayan aile üyelerinin ve arkadaşların televizyon çevresinde toplanıp oturmasından, televizyonun toplumsal yakınlığın bir ikamesi haline gelmesinden söz eder. Televizyona bağımlılıkta imgelerin, görüntünün de rolü vardır. Kavramların dolayımından kaçan görüntünün dili, sözcüklerin dilinden daha ilkeldir; televizyondaki konuşma, görsel olanın sese çevrilmesi ya da görüntünün tamamlayıcısı gibidir" (Akt: Kejanlığlu 2005, s.192). 
Kitle kültürünün temel özelliği düşüncenin anlamdan kopmuş halidir. Dergileri ve gazeteleri dolduran resimli nüktelerin neredeyse tamamı anlamdan yoksun ve amaçsız bir şekilde kitle kültürünü yeniden üretmektedir (Adorno 2017(a), s.148). Gazete, dergi, fotoğraf, film gibi yeni dolayım alanları geleneksel anlatım biçimlerinin etki alanlarına müdahale ederek gelenekseli kısıtlandırmıştır. Bu yeni dolayım biçimleri geleneksel tür anlayışının değişmesine yol açarak gelenekseli sorgulanabilir kılmıştır. Fotoğraf nasıl ki resim sanatının geleneksel görevlerinin birçoğunu ondan aldıysa kültür endüstrisinin hizmetine giren film de romanın geleneksel birçok görevini ondan almıştır (Kula, 2013:248). Dergi ve gazeteler kişilere konformist düşünceye ve toplumsal görünümlere hürmet göstermelerini; toplum düzenin sarsacak fikirlere itibar etmemelerini; bilinçsel etkiyi ortaya çıaracak motivasyonlara direnç göstermelerini istemektedir (Bloch vd. 2018, 265).

Kapitalist düzenin aklı kendi himayesine alarak istediği şekilde kullanmasını eleştiren Adorno'nun postmodern nitelikler sergilediği iddia edilmektedir (Best ve Kellner 2011, s.272-281). Modernliği eleştirmesi, aklın insanları çeşitli çıkmazlara soktuğunu göstermesi ve gelecek dünyanın öngörülerini ortaya koyması anlamında Adorno postmodern olarak değerlendirilmiştir. Aydınlanmanın sonuçlarından biri olan modern anlayış aklı ön planda tutmuş lakin aklın egemenliği ekonomik bir sömürü biçimi doğurmuştur (Kızılçelik 2000, s.206). Aydınlanma ile birlikte insanın Tanrı'nın kopyası olduğu düşüncesi varoluş üzerinde egemenliğe, Tanrısal bakışa ve buyuruculuğa yol açmıştır (Adorno ve Horkheimer, 2014, s.26). Aydınlanma ile ön plana çıkan akıl, araçsal bir hal almış; kültür endüstrisi oluşturmuş; teknolojik hegemonyanın etkisini güçlendirmiş ve bireyleri pasif hale getirmiştir.

Adorno Aydınlanma'yı mitolojik bir süreç olarak değerlendirmektedir. Ona göre Aydınlanma görece bireyi bilinçli hale getirmeye çalışmakta lakin gerçekte ise bütünselliğe bağımlı kılmaktadır. Muarız bireysel akıl henüz emekleme aşamasındayken sistem tarafından himayesine alınmış ve kitle kültürü anlayışına tabi kılınacak şekilde yeniden üretilmiştir. Aydınlanmış akıl kendi seviyesindeki bilinçle yarışabilecek herhangi bir bilinçle karşılaşamamaktadır. Dolayısıyla diğer bütün bilinçler üzerinde istediği etkiyi oluşturabilen akıl, evrensel düzenlemeyi kendi ölçülerine göre düzenlemektedir. Akıl en üst düzeyde anlamı yok eden şey olmuştur (Adorno ve Horkheimer, 2014, s.191). 


\title{
EXTENDED ABSTRACT
}

\section{The Responsibilities Of Mass Media In The Repro-duction Of The Culture Industry: The Assessment Of Theodor W. Adorno}

\author{
Ülhak Çimen \\ Atatürk University
}

Theodor Adorno is one the most important philosophers of the Frankfurt School which is known as the Institute for Social Research and Critical Theory; and the spokesman of the school on culture industry (Slater 1998). While expressing the culture industry opinion, Adorno suggests the evaluation of social conditions with a different perspective based upon the ideology. Critical consciousness is essential for the formation of this perspective. Critical consciousness needs to show that present conditions do not meet necessary conditions for the sake of humanity and it could reverse politics, economy, society and in general all the structures.

Culture industry critism of Adorno bases on the thesis that those who hold the technology and the mass media are malevolent people. The impact of culture on the social structure was gradually coming out in the period when technology and the mass media were in the development stage. It is one the most curious subjects that whether or how this impact of culture continues today. The inducement that led us to this study is to effort to understand the impact of the cultural industry in present world. Şeyda Öztürk claims that in the presentation of the book Essays on Music by Adorno, today the mass media and all technologies in general have an absolute impact on our social life and this impact is actualized by the dominance of the culture industry and hence Adorno's crticism continues to be relevant (Adorno 2018, p.19). Within this context, the study is considered important which aims to understand whether, the impact of culture on people and societies in a world where technology and the mass media are consistently developing in parallel with technology, is as emphasized by Adorno. 
The most important mainstay of Adorno's anti-system response is the culture industry analysis. According to Adorno, culture is not only a reflection of class interests, but a phenomenon that affects all components that make up society (economy, politics, art, morality, religion, etc.). The culture industry, on the other hand, explains the buying and selling of all cultural components in social life and eventually the commercialization of individuals. The philosopher considers that human, society and native culture are exploited in the culture industry. Commercialized individuals are transformed into commercial commodities by the system, categorized and uniformized and harmonized with the capitalist system.Adorno does not take a negative attitude towards technology and the mass media. What Adorno criticizes is the system that holds the technique and technology. The mass media, which propagate culture monopolies, act as catalysts for the system. The philosopher thinks that the culture industry creates injustice in the social structure and this injustice is constantly spreading by the mass production. The mass media distributing the culture industry isolates people away from face-to-face communication and subordinates the codes of the system. According to Adorno, the love of the individual and the society for the culture industry by ignoring the evil done to them has even exceeded the cunning of the system. The capitalist system no longer needs sovereignty while reification of people. Because in the world of hegemony where voluntary slavery is experienced, individuals are eager to adapt to the system.

According to the philosopher, self critism is the most reliable amongst the morals. Provided that the mind does not self criticize, the final thing is that the idea's being worthless and disapperance of the subject (Adorno 2017(a), p.132). According to Adorno, technology deactivates the active sides of people, renders the mind and thought unnecessary, atomises/reification people by making them the same and makes people suitable for the interests of the hegemonic class. For Adorno all reification is a forgetting (Jay 2014, p.411). Modern society and structure types repress people using technology successfuly, the individual mind is being suppressed and people are put into the format desired by the system (Kızılçelik 2000, p.185). The capitalist system makes sovereign a mind in which critism disappears and the subject recedes. Adorno's anti system 
moral call requires not only to allow the other to existbut also accept the other's speech, criticism and representation (Morris 2001, p.38).

In general all people, in particular individuals are now enchanted as before. The transform of people into what negates them and the internalization of this transformation ideology can only actualise with enchantment. Although the nominalist principle makes enchanted people seem individualized, it is discussed to maintain a collective social understanding. The distorted particular element which deprives itself for the sake of general, serves the distorted general element. The enchanted and reified conscious evolves to collectivity (Adorno 2016, p.313). The reality that smart individuals comply with in order to survive enchantes people. There is not any desire to reveal what the enchantment covers. Even worse people think that the reality is this enchantment. Culture industry reality endeavors confidentially in enchantment circulation amongst people in other words communication. "Today everything which is named after communication without exception is the noise that suppresses the silence of those who are kept under the influence of the enchantment. The spontaneous acts and actions of singular individuals including the ones that are supposed to be opponents, are obliged to a false activitiy, a potential imbelicity. In an externally brainwashing and similar techniques, again an externally encouraged immanent-anthropological tendency is in charge" (Adorno 2016, p.315).

According to Adorno, reification of human life is actually the success of a false ideology. The mission of the critism should be to show the main context behind culture industry in other words the mind which reproduces the system, rather than disclosing the impact in the culture industry of the ideology that enables people to reify. There is standardisation idea underlie of the culture industry. All technologies serving to culture industry (especially mass media) are being used in order to standardise the people. The system converts people, objects and all the other things into data and determines the standard criterias through conversion. In standardisation the superior mind dominates the general mind and reproduces the administered individualism. 


\section{Kaynakça / References}

Adorno, T. W.(1954). How to look at television. In The Quarterly of Film and Television, $8(3), 213-235$.

Adorno, T. W.(1991). Culture industry. London: Routledge Classics.

Adorno, T. W.(2012a). Ahlak felsefesinin sorunları. (T.Birkan, Çev.), İstanbul: Metis Yayınları.

Adorno, T. W.(2012b). Walter Benjamin üzerine. (D. Muradoğlu, Çev.), İstanbul: Yapı Kredi Yayınları.

Adorno, T. W.(2016). Negatif diyalektik. (Ş. Öztürk, Çev.), İstanbul:Metis Yayınclık.

Adorno, T. W.(2017a). Minima moralia.(O. Koçak ve A.Doğukan, Çev.), İstanbul: Metis Yayınları.

Adorno, T.W.(2017b). Metafizik kavram ve sorunlar. (İ. Serin, Çev.), İstanbul: İthaki Yayınları.

Adorno, T.W.(2018). Müzik yazıları. (Ş Öztürk, Çev.), İstanbul:Yapı Kredi Yayınları.

Adorno T. W. ve Horkheimer M.(2013). Teori ve pratik üzerine bir tartı̧̧ma (1956). (Orhan Kılıç, Çev.), İstanbul: Metis Yayınları

Adorno T.W. ve Horkheimer M.(2014). Aydınlanmanm diyalektiği. (N.Ülner ve E. Ö. Karadoğan, Çev.), İstanbul: Kabalcı Yayınları.

Benzer, M.(2011). The sociology of theodor Adorno. New York: Cambridge University Press.

Best S. ve Kellner D. (2011). Postmodern teori eleştirel soruşturmalar. (M. Küçük, Çev.), İstanbul: Ayrınt Yayınları.

Bloch, E., Lukâcs G. Brecht B.t., Benjamin W. ve Adorno T.(2018). Estetik ve politika. (E. Gen, T. Belge, B.Aksoy Çev.), İstanbul: İletişim Yayınları.

Fraser, I.(2018). Political theory and film from Adorno to Žižek. London: Rowman \& Littlefield International Ltd.

Hansen, M. B.(2012). Cinema and experience Siegfried Kracauer, Walter Benjamin, and Theodor W. Adorno. London: University of California Press.

Huhn, T.(2006). The Cambridge companion to Adorno. New York: Cambridge University Press.

Jay, M.(2014). Diyalektik imgelem, Frankfurt Okulu'nun tarihi ve çalısmalar[1923-1950].

(S.DoğanÇev.), İstanbul: Ayrıntı Yayınları.

Kejanlığlu, B.(2005). Frankfurt Okulu'nun eleştirel bir uğrağı iletişim ve medya. Ankara: Bilim ve Sanat Yayınları.

Kızılçelik, S.(2000). Frankfurt okulu: Eleştirel Teori) Ankara: Anı Yayıncllı.

Kula, O.B.(2013). Marx, Benjamin, Adorno sanat ve edebiyat. İstanbul: Türkiye İş Bankası Kültür Yayınları. 
Miklitsc, R.(2006). Roll Over Adorno Critical theory, popular culture, audiovisual media. Albany: State University of New York Press.

Morris, M.(2001). Rethinking the communicative turn Adorno, Habermas, and The problem of communicative freedom. New York: State University of New York Press.

Slater, P.(1998). Frankfurt Okulu kökeni ve önemi marksist bir yaklaşım. (A.Özden Çev.), İstanbul: Kabalc Yayınevi.

Wall, B.(2013). Theodor Adorno and film theory the fingerprint of spirit. USA: Palgrave Macmillan.

Wilson, R.(2007). Theodor Adorno. New York: Routledge Pub.

Witkin, R. W. (2003). Adorno on popular culture. London: Routledge Pub.

\section{Kaynakça Bilgisi / Citation Information}

Çimen, Ü. (2020). Kültür endüstrisinin yeniden üretiminde kitle iletişim araçlarının görevleri: Theodor W. Adorno değerlendirmesi. OPUS-Uluslararası Toplum Araştırmaları Dergisi, 16(29), 2316-2345. DOI: 10.26466/opus.706877 